\title{
Analysis on the Interaction between Human Resource Management and Performance in Enterprise
}

\author{
Jian Li \\ Qilu Normal University \\ (Shandong,China 250013)
}

Keywords: Human resource management; Performance management; Management dimension

\begin{abstract}
Human resource management is always the core issue of the organization in any organization regardless of size. Under the new situation, for efficient and effective management of enterprise human resources, the way to make the role of human resources into full play means to improve the efficiency of enterprises, and it refers to have long lagged behind the western developed countries. Based on the study of human resource management and performance management in enterprise, this paper explores the relationship between human resource management and performance management.

with who the work of the enterprise and the activities are completed. It is no exaggeration to say that the core of enterprise management is human resource management. As the most direct basis for each enterprise, performance means to measure the level of staff determining the remuneration of employees which is the most closely related to the enterprise system. Good performance management system can effectively mobilize the enthusiasm and creativity of employees, but also for enterprises to achieve greater benefits and lay a solid foundation. Therefore, clarifying the relationship between human resource management and performance is the most important part of the research and reform of enterprise organization system.
\end{abstract}

\section{Introduction of Enterprise Human Resource Management}

Human resources. There are some differences in the definition of human resources according to the different dimensions. From the social perspective, it refers to a country or region which can be engaged in labor to create value to create material and spiritual wealth for the community population. And from the enterprise perspective, human resources generally refers to the practical working capacity of the people. In my opinion, human resources can be defined as a set of intellectual strength that can be developed and utilized by organizations or individuals.

To carry out production and business activities, enterprises needs a variety of resources, and human resources is one of the most important which is also a relatively strange. Scholars concluded that the characteristics of human resources are: firstly, looking initiative as human resources with conscious. The purpose of power can take the initiative to choose their own behavior which can also keep learning progress. Secondly, timeliness, human resources and human life are closely related only after the adult who can make the appropriate labor to a certain age to retire. Thirdly, the times, human resources play a role by the society the environmental impact that was specific, restricted by the level of social development. Fourthly, value added, people can get higher after exercise physical strength, intelligence, experience and skills, and these will not disappear with practice. Fifthly, development, education and training are the main means of human resource development, and the use of human resources helps to the development of human resources.

Introduction of human resource management. Human resource management is a combination of planning, organization, management, command, coordination and control. Human resource management is the core of the rational allocation of human resources within the enterprise, so that each job has the right people to play the maximum effectiveness of human resources. The whole management process includes the acquisition of human resources, training, effectiveness, rewards ,punishments and so on. Generally speaking, it can be divided into the following aspects:

1)The human resources management plan. In order to organize correct the development strategy of the organization according to the change of internal and external environment of the organization, the use of scientific and effective means for the management of human resources, policies and 
measures suitable to develop, so that the enterprise human resources can achieve a balance between supply and demand with efficient operation of the state. In short, each position corresponds to the appropriate personnel, so that it will have efficient allocation of human resources

2)The job analysis. Investigation and research of the system for various positions of the nature, tasks, responsibilities and the relationship required staff knowledge, skills, experience and so on, and use the scientific method for plan and record. Job analysis is the core and foundation of the whole human resource management, and a complete job analysis is helpful for the enterprise to make reasonable decisions on human resources, such as personnel recruitment, training, compensation standards and so on.

3)The recruitment of personnel. According to the post research, through a variety of means, the use of a variety of channels in the community to attract qualified personnel to enter the enterprise. Personnel recruitment, according to the needs of enterprises and the current situation of the human resources market, comes from the vast number of people to find the right candidate. This is an extremely difficult but important task. Good recruitment behavior not only can get high-quality talent, but also can improve the visibility of the enterprise.

4)The training of personnel. As the name suggests, it is the ability of a business organization to make employees complete the work that is or will be done in a variety of ways. In order to improve the staff's ability to work, so that employees get better performance, and ultimately improve the performance of the entire business organization, personnel training for each enterprise is the most important. Personnel training is not only in the new staff that can be completed when the staff training with the entire career life cycle. Personnel training for members of the organization obtain professional promotion and strengthen professional ability to make a guarantee.

5)The performance management. According to the staff to complete the work and other performance to determine the remuneration of employees, it is performance management which is the core of human resources management organization. All in the modern enterprise, the performance management of the main goal is to retain the value of employees and employee motivation making excellent employees to continuously improve work efficiency and obtain better returns, but also for the organization, enterprise, society and country to make greater contributions.

6)Management of labor relations. Labor relation is a kind of social economic interest relation, its essence is a kind of interaction between the manager and the manager which is named as the manager and the worker. Because of the interests of both sides, so that labor relations can be expressed as cooperation. Management of labor relations needs to build a harmonious relationship between enterprises to reduce internal losses.

\section{Introduction of Organizational Performance Management}

Performance. In short, performance is the result of employee behavior. For different companies, different concerns about start-up companies which will pay more attention to the results, and for mature enterprises, it is more focused on the process. Performance includes three aspects organizational performance, group performance and employee performance. This paper focuses on organizational performance. As the name suggests, organizational performance is the overall performance of the organization. In the business organization, the level of organizational performance can show the level of organizational profitability, operating level, sustainable development and so on. In today's increasingly fierce market competition, organizational performance is one of the important indicators to measure the status of the organization, and organizational performance determines the status and future of the organization in the market.

The way to evaluate organizational performance. To evaluate the performance of an organization, the following principles should be followed some principles, such as the principle of highlighting key points. The organization performance evaluation contains multiple indexes, add all the indicators is not possible in the evaluation process, and it must choose the contribution degree, weight index of high index from all indicators as a measure of organizational performance standards. According to each organization development, development goals to develop specific indicators of performance management. The relative independence principle between organizational performance indicators should be independent of each other, not statistically significantly correlated, if there is a significant correlation between indicators, it will increase the overlap between indicators, performance 
evaluation of inaccuracy, and increase the workload. The establishment of organizational performance evaluation system make sure the practical and effective method without ambitious which means it pays attention to the timing, and power line is concise. The comprehensive principle, performance evaluation system should be set as the actual situation of comprehensive and accurate response, otherwise it will cause evaluation of major direction of migration to set up the system.

\section{The Relationship between Human Resource Management and Performance Management}

Research on the relationship between human resource management and performance management, domestic and foreign scholars have different conclusions. In view of the position and angle of the scholars, the conclusions are different. These conclusions can explain the relationship between human resource management and performance management to a certain extent. Now about the relationship between the two aspects there are several aspects of the following:

1) In most studies, human resource management is regarded as the purpose, and the performance management as a means. But for human resources management, so far, there is no generally accepted definition about what efforts should be done. Because of different objects, or business entity, or organization form, enterprise performance management, different scholars use the indicators which are not the same, and there is no uniform standard on the selection of these indicators.

2) Most of the researches focus on the whole organization, but pay little attention to the role of the individual in the study of the relationship between human resource management and performance management. It is widely believed that the study of the performance of the whole organization, with more than a single comprehensive effect on the individual performance of the organization, so that in future research, it must research in related fields pay more attention.

3)Cultural differences lead to differences in research results. The western developed countries advocate individualism and liberalism, while our country advocates collectivism. Because of the different culture leading to the two party business practices differ greatly, the two party enterprise culture to replace each other which is easy to produce the effect of this, business practice in China in recent thirty years gets the successful experience. Therefore, scholars at home and abroad are mostly based on their own regional enterprises.

\section{Suggestions on Improving Human Resource Management through Performance Management}

If enterprises want to achieve efficient human resource management, they must have a set of performance management system that can attract talents and retain talents. The suggestions presented in this paper are as follows:

Establish and improve the enterprise management system.. The most important component of the enterprise is the staff at all levels which only to allow employees at all levels to participate effectively in the process of enterprise management, operation and decision-making in order to ensure corporate democracy. For managers, they can understand the real demands of employees, and employees can improve their sense of responsibility, sense of mission and self-confidence and further enhance their corporate identity. To correctly implement the system, it must first get the attention of business managers and listen to the views of the general staff to provide the necessary facilities for employees to participate in business affairs to enhance the cohesion of enterprises.

Establish and improve the performance appraisal mechanism. Performance is closely related to employee compensation. Reasonable performance management system can effectively improve the enthusiasm of employees, and the bad performance management system will lead to the demise of enterprises. A good performance management system should be clear and definite, and the manager can encourage and punish the employee by this, and thus, the employee will be able to make clear their own work objectives and increase their initiative. 


\section{Conclusion}

Performance management as an important means of human resource management is paid attention to by various business organizations. It must adhere to the people-oriented, and for the welfare of employees, it helps for the interests of the owners to consider, the formation of efficient human management system, the benefit of employees, the benefit of the enterprise and the benefit of society.

\section{References}

[1] [1]Yazhou Wang, Jian Lin.Human resource management practices, knowledge management and corporate performance[J]. Scientific Research Management,2014,02:136-144.

[2] [2]Yulei Li, Leping Yuan.Research on the impact of strategic human resource management on Enterprise Performance[J].Statistical Research,2013,10:92-96.

[3] [3]Junpu Chen. Research on the impact of strategic human resource management on Enterprise Performance[D].Henan University,2015.

[4] [4]Hongmei Zhao.Research on the relationship between human resource management and organizational performance[D].Xi'an Polytechnic University,2011.

[5] [5]Dege Liu. Research on the relationship between human resource management and enterprise performance[D]. Wuyi University,2008.

[6] [6]Qin Meng, Mengshu Lu, Mengdi Wen.Study on the relationship between human resource management system and performance in enterprise[J].Chinese collective economy,2014,36:102-103 